\title{
Placental Volume Measurement in Clinical Practice
}

\author{
1Junichi Hasegawa, ${ }^{2}$ Tatsuya Arakaki, ${ }^{3}$ Masamitsu Nakamura, ${ }^{4}$ Hiroko Takita, ${ }^{5}$ Akihiko Sekizawa
}

\begin{abstract}
Measurement of the placental volume during pregnancy can occasionally predict adverse outcomes, including ischemic and restricted conditions in the fetus and placenta later in pregnancy. Three-dimensional (3D) sonographic evaluation of the placental volume during the first trimester is a simple and rapid procedure that is commonly applied, but its use during the second trimester seems to be limited. The placental volume can be obtained within 5 minutes as part of daily clinical practice. Combining screening with the placental volume and other markers can increase the rate of detection of fetal and placental anomalies. In this article, we review the prediction of adverse maternal and fetal outcomes later in pregnancy using 3D sonographic measurement of the placental volume.
\end{abstract}

Keywords: First trimester screening, Hypertension, Placental volume, Pre-eclampsia, Three-dimensional, Uterine artery.

How to cite this article: Hasegawa J, Arakaki T, Nakamura M, Takita H, Sekizawa A. Placental Volume Measurement in Clinical Practice. Donald School J Ultrasound Obstet Gynecol 2015;9(4):408-412.

Source of support: This study was funded by JSPS KAKENHI Grant number 15K10688.

Conflict of interest: None

\section{INTRODUCTION}

Adversely affected placental growth affects the fetal growth. Fetal growth restriction is a result of inadequate placental development in many cases. However, the placental weight is usually not decreased in restricted fetuses due to major fetal morphological abnormalities. On the other hand, the neonatal birth weights are likely to be low when there are maternal, uterine, placental or umbilical cord abnormalities concomitant with a low placental weight. ${ }^{1}$

It is considered that the fetal growth is strongly dependent on the placental development or function. Placental abnormalities, such as placental abruption, hematoma, a

\footnotetext{
${ }^{1}$ Associate Professor, ${ }^{2-4}$ Assistant Professor

${ }^{5}$ Professor and Chairman

${ }^{1}$ Department of Obstetrics and Gynecology, St. Marianna University School of Medicine, Kanagawa, Japan

${ }^{2-5}$ Department of Obstetrics and Gynecology, Showa University School of Medicine, Tokyo, Japan
}

Corresponding Author: Junichi Hasegawa, Associate Professor, Department of Obstetrics and Gynecology St. Marianna University School of Medicine, Kanagawa, Japan Phone: +81-44-977-8111, e-mail: hasejun@oak.dti.ne.jp lobed placenta, etc. usually reduce the placental weight due to atrophic or ischemic changes, although some complications related to neoplasms, such as chorioangioma, may increase the weight of the placenta. ${ }^{1}$

When there are no obvious abnormalities in the fetus or placenta, placental dysfunction due to unknown or some multifactorial adverse factors, such as that affecting the uteroplacental perfusion from early gestation, should be suspected. Maternal genetic, anatomical, physiological or lifestyle factors, such as a low maternal body mass index, weight loss during pregnancy, alcohol consumption and pre-eclampsia, might have adverse effects on the fetal and placental development. Similar to growth-restricted fetuses complicated with placental structural abnormalities, the placental weight is likely to be low even in the absence of placental structural abnormalities in growth-restricted fetuses, ${ }^{1}$ because fetal growth restriction is usually caused by inadequate placental development and placental growth from early gestation, rather than a functional disorder of the placenta.

Therefore, measurement of the placental volume during pregnancy may occasionally be able to predict adverse outcomes, including ischemic and restricted conditions, in the fetus and placenta later in pregnancy. In this article, we review the prediction of adverse maternal and fetal outcomes later in pregnancy using three-dimensional (3D) sonographic measurement of the placental volume.

\section{MEASUREMENT OF THE PLACENTAL VOLUME}

Several 3D ultrasound methods available in daily clinical practice have been reported, including virtual organ computer-aided analysis (VOCAL) and extended imaging virtual organ computer-aided analysis (XI VOCAL) ${ }^{2-5}$ Volume measurements using 3D ultrasound methods are much more accurate than those using two-dimensional (2D) ultrasound for both regularly- and irregularlyshaped objects. ${ }^{6,7}$

The 3D volume of the placenta was measured by transabdominal ultrasonography based on the example described in previous reports. ${ }^{8,9}$ The sweep angle was set at $85^{\circ}$, and it was directed perpendicular to the placental plate. The VOCAL technique was then used to obtain a sequence of six sections of the placenta, each after a $30^{\circ}$ rotation from the previous section. In each of the six planes, the contour of the placenta was drawn by manual tracing, taking care to exclude the uterine wall, which 
at this point of gestation is usually thickened under the placenta, either because of hypertrophy or contraction. The software program calculates the volume from the areas highlighted in each of the six planes, and when the calculation was finished, the computed reconstruction of the scan was performed (Fig. 1).

Usually, volume assessments are performed after 11 weeks of gestation as a first-trimester ultrasound screening, because the chorionic villous trophoblasts becomes distinguishable from smooth chorions at this stage. On the other hand, there have been some reports that assessed the placental volume before 10 weeks of gestation. ${ }^{10,11}$ It was also reported that pregnancies ending in miscarriage had a smaller trophoblast volume at 6 to 12 weeks of gestation as well as reduced trophoblast growth compared with those that result in live birth. ${ }^{11}$ However, it is thought that the usability of placental assessment before 10 weeks of gestation in the daily clinical setting is limited.

\section{RELATIONSHIP BETWEEN THE PLACENTAL VOLUME IN THE FIRST TRIMESTER AND PERINATAL OUTCOMES}

Although there is some variability in placental volume measurement and a relatively wide standard deviation, the placental volume can be assessed by 3D ultrasound at 11 to 13 weeks of gestation with minimal deviations ${ }^{12}$ compared with that assessed later in pregnancy. Thus, many studies mentioned the possibility of placental volume measurement as a predictor of an adverse pregnancy outcome when performed late in the first trimester. ${ }^{13-15}$

\section{Predicting Fetal Growth Restriction}

There have been previous studies on the prediction of growth restriction in fetuses using placental volume measurement in the first trimester. ${ }^{13-17}$ Schwartz et al ${ }^{15}$ demonstrated that a placental quotient (= placenta volume/crown-rump length) less than 1.00 predicted a small-for-gestational age (SGA) fetus with 56.5\% sensitivity, $75 \%$ specificity and a $31.7 \%$ positive predictive value. Plasencia et $\mathrm{al}^{18}$ reported that measurement of the placental volume and serum pregnancy-associated plasma protein-A (PAPP-A) can improve the prediction of the birth of small or large-for-gestational age (SGA) or (LGA) neonates.

\section{Predicting Hypertensive Disorder}

Pre-eclampsia is a systemic maternal disease that develops after the second trimester, but it has recently been thought that pre-eclampsia originates in the placenta itself, starting with inadequate cytotrophoblast invasion and ending with widespread maternal endothelial dysfunction beginning from the first trimester. ${ }^{19,20}$ Therefore, uterine artery Doppler findings have often been used to predict the development of hypertensive disorder later in pregnancy. It was demonstrated that the placentas of patients with pathological uterine perfusion in the second trimester were already remarkably smaller at the end of the first trimester than those of healthy patients. ${ }^{17}$ Both unilateral and bilateral 'notching' are associated with a significantly smaller placenta in the first trimester. ${ }^{17}$ In fact, some studies supported the possibility of placental

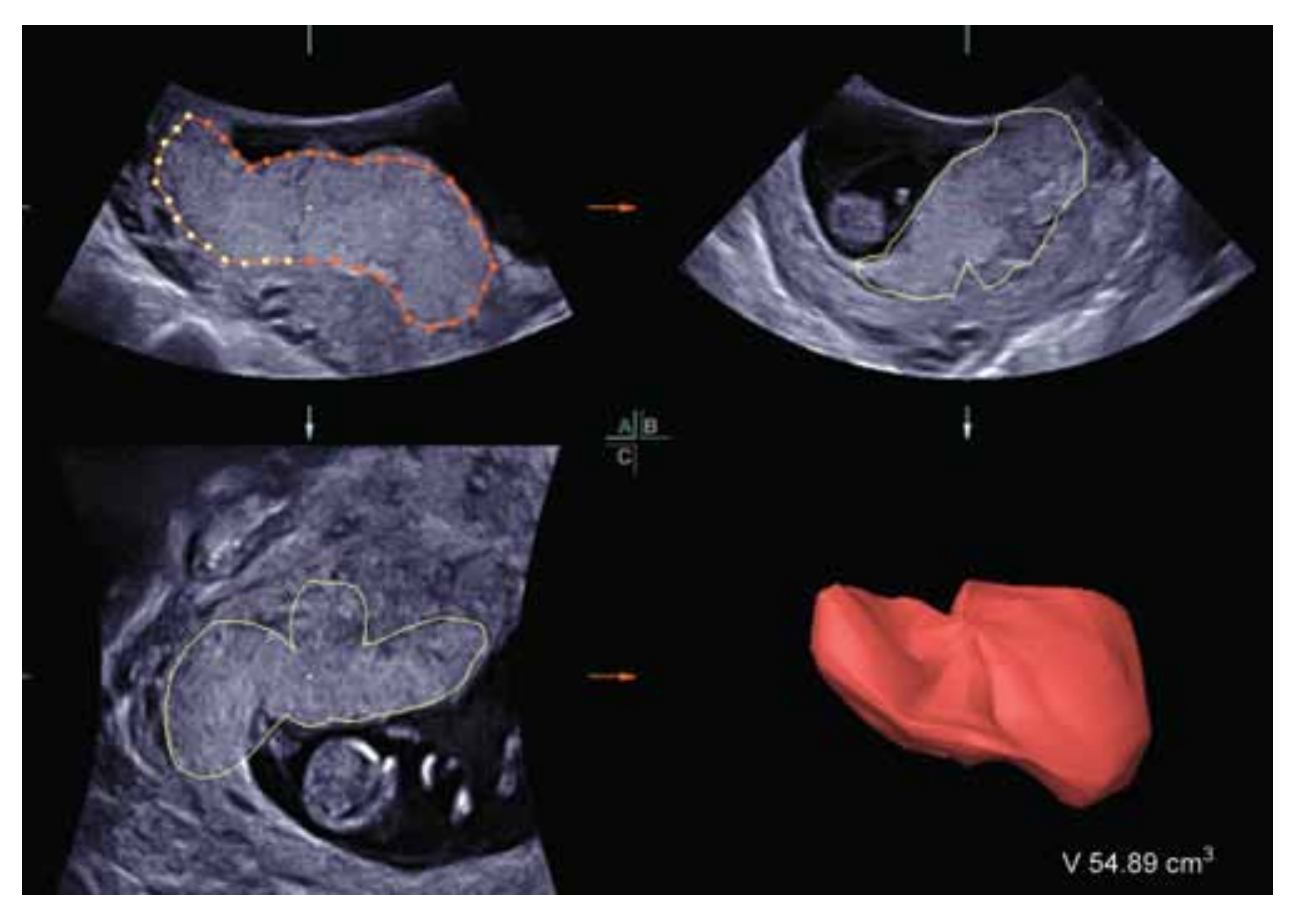

Fig. 1: Three-dimensional measurement of the placental volume 
volume measurement as a predictor of fetal growth restriction in the first trimester, ${ }^{15,21}$ while one report mentioned that placental volume measurement at 12 weeks was insufficient for screening in a low-risk population, although it had a potential advantage compared with performing the procedure during the second trimester. ${ }^{14}$

Since uterine artery Doppler ultrasonography in the first trimester is more sensitive for the prediction of pre-eclampsia, ${ }^{14}$ the combination of the uterine artery pulsatility index (PI) and placental volume gave better results compared to the single use of one of these parameters. ${ }^{13,22}$ Furthermore, the prediction rates for pregnancy-induced hypertension $(\mathrm{PIH})$ using ultrasound and biochemical markers during the first trimester could be further increased. Scazzocchio et $\mathrm{al}^{23}$ demonstrated a detection rate of $69.2 \%$ for early-onset pre-eclampsia with a $5 \%$ false-positive rate by a first-trimester screening procedure combining maternal factors with the maternal blood pressure, uterine artery Doppler and PAPP-A.

Arakaki et $\mathrm{al}^{21}$ reported the detection rate for $\mathrm{PIH}$ using the placental volume and uterine artery Doppler at 11 to 13 weeks' gestation. The placental volume measurement was significantly smaller in the early- and late-onset PIH groups than in the unaffected cases $\left(43\right.$ vs $\left.62 \mathrm{~cm}^{3}\right)$, but these parameters were not significantly different between the late-onset PIH and unaffected cases ${ }^{21}$ (Fig. 2). When the combination of factors was used, the detection rate for early-onset PIH was $67.5 \%$ with a $5 \%$ false-positive rate ${ }^{21}$ the same as the detection rate in the first trimester ultrasound screen combining the maternal blood pressure, uterine artery Doppler and serum marker levels.

\section{SCREENING FOR CHROMOSOMAL ABNORMALITIES}

Some previous reports suggested that placental volume measurement may prove to be useful in the first trimester

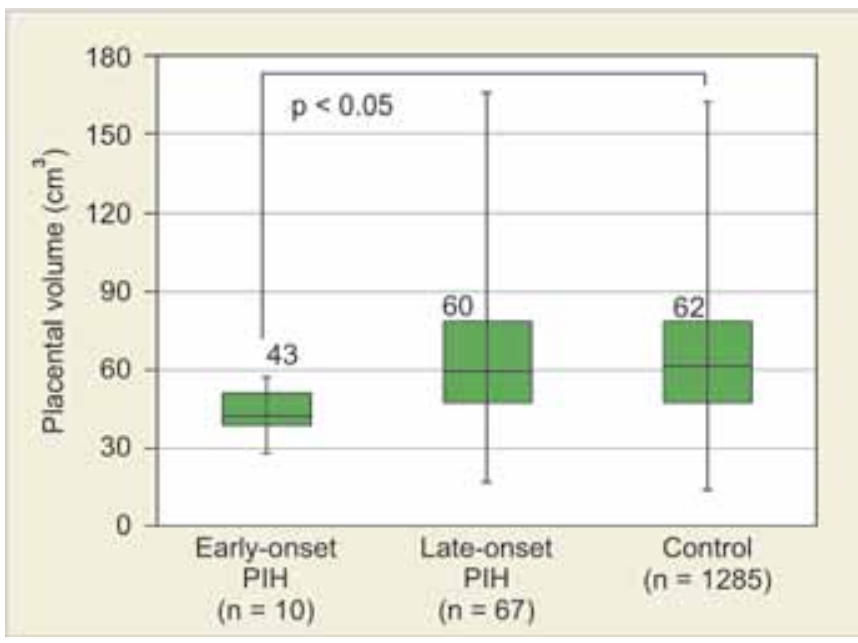

Fig. 2: Placental volume at 11 to 13 weeks' gestation in earlyand late-onset of pregnancy-induced hypertension screening for chromosomal anomalies. ${ }^{9,24,25}$ Wegrzyn et al demonstrated that measurement of the placental volume at 11 to $13+6$ weeks of gestation was unlikely to be a useful predictor of trisomy 21 and Turner syndrome, but concluded that in trisomies 13 and 18, the small placental volume might be due to early-onset fetal growth restriction, which could be the consequence of impaired placental function. ${ }^{24}$

\section{RELATIONSHIP BETWEEN THE PLACENTAL VOLUME IN THE SECOND TRIMESTER AND PERINATAL OUTCOMES}

The placental volume obtained using $3 \mathrm{D}$ ultrasound was between 77.7 and $213.9 \mathrm{~cm}^{3}$ at 14 to 25 weeks' gestation. ${ }^{26}$ Generally, it is considered to be difficult to measure the placental volume late in the second trimester, because the placenta develops widely in the uterus. A large placenta is often not visualized within the angle of the ultrasound probe, especially when the placenta is located on both sides of the uterine wall.

Cases with fetal growth restriction that become obvious after mid-gestation are often caused by not only inadequate cytotrophoblast invasion and early placental development, but also by various environmental factors, such as the maternal lifestyle and uteroplacental conditions. For instance, the pathophysiology of growth-restricted fetuses with obstructive pathological umbilical cord abnormalities is explained by thrombotic vasculopathy, which is characterized by either the absence or degeneration of fetal capillaries in groups of contiguous terminal villi with a distribution consistent with upstream vascular occlusion. ${ }^{27,28}$ In addition, as mentioned previously, the placental volume in the late-onset PIH cases was not significantly different from that in the unaffected cases. ${ }^{21}$ This study provides support for the hypothesis that PIH may have different etiologies, with early- and late-onset PIH representing distinct entities. ${ }^{18,22,24,29}$ Placental volume measurement is not satisfactory for predicting poor perinatal outcomes which only present symptoms later in pregnancy, although the placenta tends to be smaller both earlier and later in pregnancy in these cases.

Hafner et a ${ }^{30}$ investigated the value of second trimester (16-23 weeks' gestation) 3D sonographic placental volume measurements to predict infants that will be below the 10th centile for birth weight. The values for the specificity and sensitivity achieved by choosing an 'optimal' cut-off point for the estimation probability for a SGA infant were low, at 82.5 and $52.5 \%$ respectively. Moreover, in a comparison of the value of the 3D placental volume at 12 weeks with uterine artery Doppler at 22 weeks in a low-risk population, it was revealed that similar sensitivities for predicting pre-eclampsia and fetal growth restriction existed. ${ }^{14}$ 
The use of the screening approach using the 3D placental volume is associated with several limitations in clinical practice. Although it has been reported that the intra- and interclass correlation coefficients (ICCs) for the ultrasound measurement of placental volume were not low $(0.7-0.9),{ }^{8}$ the reproducibility would vary with advancing gestation. Moreover, the sensitivity and specificity to detect patients with poor outcomes using only 3D ultrasound evaluations has been unsatisfactory. There have been some reports that evaluated the perinatal outcomes using the placental Doppler vascularity. ${ }^{31-34}$ Further research to evaluate not only the placental volume but also the placental function is required.

\section{CONCLUSION}

The 3D sonographic evaluation of the placental volume in the first trimester is a simple and rapid method, but measurements in the second trimester seem to be of limited use. Usually, the placental volume can be obtained within 5 minutes as part of daily clinical practice. We believe that using a combination of screening methods with the placental volume and other markers can increase the detection rate for perinatal adverse outcomes, such as SGA and PIH.

\section{REFERENCES}

1. Hasegawa J, Arakawa K, Nakamura M, Matsuoka R, Ichizuka K, Katsufumi O, Sekizawa A, Okai T. Analysis of placental weight centiles is useful to estimate cause of fetal growth restriction. J Obstet Gynaecol Res 2011;37(11):1658-1665.

2. Hafner E, Schuchter $K$, van Leeuwen $M$, Metzenbauer $M$, Dillinger-Paller B, Philipp K. Three-dimensional sonographic volumetry of the placenta and the fetus between weeks 15 and 17 of gestation. Ultrasound Obstet Gynecol 2001;18(2):116-120.

3. Metzenbauer M, Hafner E, Hoefinger D, Schuchter K, Stangl G, Ogris E, Philipp K. Three-dimensional ultrasound measurement of the placental volume in early pregnancy: method and correlation with biochemical placenta parameters. Placenta 2001;22(6):602-605.

4. Nowak PM, Nardozza LM, Junior AE, Rolo LC, Moron AF. Comparison of placental volume in early pregnancy using multiplanar and VOCAL methods. Placenta 2008;29(3):241-245.

5. Cheong KB, Leung KY, Li TK, Chan HY, Lee YP, Tang MH. Comparison of inter- and intraobserver agreement and reliability between three different types of placental volume measurement technique (XI VOCAL, VOCAL and multiplanar) and validity in the in vitro setting. Ultrasound Obstet Gynecol 2010;36(2):210-217.

6. Riccabona M, Nelson TR, Pretorius DH, Davidson TE. Distance and volume measurement using three-dimensional ultrasonography. J Ultrasound Med 1995;14(12):881-886.

7. Riccabona M, Nelson TR, Pretorius DH, Davidson TE. In vivo three-dimensional sonographic measurement of organ volume: validation in the urinary bladder. J Ultrasound Med 1996;15(9):627-632.
8. Nakamura M, Hasegawa J, Hamada S, Matsuoka R, Ichizuka K, Sekizawa A, Okai T. The volume of the chorion villosum is associated with the location of the umbilical cord in the first trimester. Prenat Diagn 2013;33(8):759-763.

9. Metzenbauer M, Hafner E, Schuchter K, Philipp K. Firsttrimester placental volume as a marker for chromosomal anomalies: preliminary results from an unselected population. Ultrasound Obstet Gynecol 2002;19(3):240-242.

10. Nardozza LM, Nowak PM, Junior AE, Filho GHA, Rolo LC, Torloni MR, Moron AF. Evaluation of placental volume at 7 to $10+6$ weeks of pregnancy by 3D-sonography. Placenta 2009;30(7):585-589.

11. Reus AD, El-Harbachi H, Rousian M, Willemsen SP, SteegersTheunissen RP, Steegers EA, Exalto N. Early first-trimester trophoblast volume in pregnancies that result in live birth or miscarriage. Ultrasound Obstet Gynecol 2013;42(5):577-584.

12. Burstein E, Sheiner E, Hershkovitz R. Three-dimensional placental volume measurements between 11 and 13 weeks' gestation. Am J Perinatol 2009;26(2):169-171.

13. Schuchter K, Metzenbauer M, Hafner E, Philipp K. Uterine artery Doppler and placental volume in the first trimester in the prediction of pregnancy complications. Ultrasound Obstet Gynecol 2001;18(6):590-592.

14. Hafner E, Metzenbauer M, Hofinger D, Stonek F, Schuchter K, Waldhor T, Philipp K. Comparison between three-dimensional placental volume at 12 weeks and uterine artery impedance/ notching at 22 weeks in screening for pregnancy-induced hypertension, pre-eclampsia and fetal growth restriction in a low-risk population. Ultrasound Obstet Gynecol 2006;27(6): 652-657.

15. Schwartz N, Coletta J, Pessel C, Feng R, Timor-Tritsch IE, Parry S, Salafia CN. Novel 3-dimensional placental measurements in early pregnancy as predictors of adverse pregnancy outcomes. J Ultrasound Med 2010;29(8):1203-1212.

16. Law LW, Leung TY, Sahota DS, Chan LW, Fung TY, Lau TK. Which ultrasound or biochemical markers are independent predictors of small-for-gestational age? Ultrasound Obstet Gynecol 2009;34(3):283-287.

17. Hafner E, Metzenbauer M, Dillinger-Paller B, Hoefinger D, Schuchter K, Sommer-Wagner H, Philipp K. Correlation of first trimester placental volume and second trimester uterine artery Doppler flow. Placenta 2001;22(8-9):729-734.

18. Plasencia W, Maiz N, Poon L, Yu C, Nicolaides KH. Uterine artery Doppler at $11+0$ to $13+6$ weeks and $21+0$ to $24+6$ weeks in the prediction of pre-eclampsia. Ultrasound Obstet Gynecol 2008;32(2):138-146.

19. Brosens IA. Morphological changes in the utero-placental bed in pregnancy hypertension. Clin Obstet Gynaecol 1977;4(3): 573-593.

20. Wang A, Rana S, Karumanchi SA. Pre-eclampsia: the role of angiogenic factors in its pathogenesis. Physiology 2009;24: 147-158.

21. Arakaki T,Hasegawa J,Nakamura M,HamadaS,Muramoto M, Takita H, Ichizuka K, Sekizawa A. Prediction of early- and late-onset pregnancy-induced hypertension using placental volume on three-dimensional ultrasound and uterine artery Doppler. Ultrasound Obstet Gynecol 2015;45(5):539-543.

22. Rizzo G, Capponi A, Cavicchioni O, Vendola M, Arduini D. First trimester uterine Doppler and three-dimensional ultrasound placental volume calculation in predicting pre-eclampsia. Eur J Obstet Gynecol Reprod Biol 2008;138(2):147-151. 
23. Scazzocchio E, Figueras F, Crispi F, Meler E, Masoller N, Mula R, Gratacos E. Performance of a first-trimester screening of pre-eclampsia in a routine care low-risk setting. Am J Obstet Gynecol 2013;208(3):203e201-203e210.

24. Wegrzyn P, Faro C, Falcon O, Peralta CF, Nicolaides KH. Placental volume measured by three-dimensional ultrasound at 11 to $13+6$ weeks of gestation: relation to chromosomal defects. Ultrasound Obstet Gynecol 2005;26(1):28-32.

25. Gassner R, Metzenbauer M, Hafner E, Vallazza U, Philipp K. Triploidy in a twin pregnancy: small placenta volume as an early sonographical marker. Prenat Diagn 2003;23(1):16-20.

26. Zalud I, Shaha S. Placental and spiral artery volume and grayscale value assessment via 3-dimensional sonography in the second trimester. J Clin Ultrasound 2007;35(9):504-508.

27. Redline RW, Pappin A. Fetal thrombotic vasculopathy: the clinical significance of extensive avascular villi. Hum Pathol 1995;26(1):80-85.

28. Redline RW. Clinical and pathological umbilical cord abnormalities in fetal thrombotic vasculopathy. Hum Pathol 2004;35(12):1494-1498.
29. Melchiorre K, Wormald B, Leslie K, Bhide A, Thilaganathan B. First-trimester uterine artery Doppler indices in term and preterm pre-eclampsia. Ultrasound Obstet Gynecol 2008; 32(2):133-137.

30. Hafner E, Philipp T, Schuchter K, Dillinger-Paller B, Philipp K, Bauer P. Second-trimester measurements of placental volume by three-dimensional ultrasound to predict small-for-gestationalage infants. Ultrasound Obstet Gynecol 1998;12(2):97-102.

31. Hata T, Tanaka H, Noguchi J, Hata K. Three-dimensional ultrasound evaluation of the placenta. Placenta 2011;32(2):105-115.

32. Welsh AW, Humphries K, Cosgrove DO, Taylor MJ, Fisk NM. Development of three-dimensional power Doppler ultrasound imaging of fetoplacental vasculature. Ultrasound Med Biol 2001;27(9):1161-1170.

33. Matijevic R, Kurjak A. The assessment of placental blood vessels by three-dimensional power Doppler ultrasound. J Perinat Med 2002;30(1):26-32.

34. Konje JC, Huppertz B, Bell SC, Taylor DJ, Kaufmann P. Threedimensional colour power angiography for staging human placental development. Lancet 2003;362(9391):1199-1201. 